\title{
Targeting area and comparing the effect of different land use/land cover (LULC) scenarios on greenhouse gases (GHGs) emission reduction (Case study: Hyrcanian forests in Iran)
}

Hamidreza Kamyab ( $\sim$ hrkamyab@gau.ac.ir)

Gorgan University of Agricultural Sciences and Natural Resources https://orcid.org/0000-0002-94454980

\section{Zahra Asadolahi}

Lorestan University

\section{Research}

Keywords: Deforestation, Land Change Modeler, Multi Criteria Evaluation, Ecosystem Services, IPCC, REDD

Posted Date: November 20th, 2020

DOI: https://doi.org/10.21203/rs.3.rs-108537/v1

License: (c) (1) This work is licensed under a Creative Commons Attribution 4.0 International License.

Read Full License 


\section{Targeting area and comparing the effect of different land}

use/land cover (LULC) scenarios on greenhouse gases (GHGs) emission reduction (Case study: Hyrcanian forests 2 in Iran)

Hamidreza Kamyab ${ }^{1}$, Zahra Asadolahi ${ }^{2}$

${ }^{1}$ Department of Environmental Science, Faculty of Fisheries and Environmental science, Gorgan University of Agricultural Sciences and Natural Resources, Golestan, Iran.

${ }^{2}$ Department of Environment and Fisheries, Faculty of Agriculture and Natural Resources, Lorestan University, Khorram Abad, Iran.

Abstract

Background: Because the greenhouse gases (GHGs) emissions are known to be strongly influenced by land use/land cover (LULC) change, reducing emissions from 13 deforestation and degradation (REDD) mechanism has attracted much attention as a 14 strategy for understanding how different LULC scenarios effect on the GHGs emissions. 15 Transition to other LULC types is one of the major challenges of Iran's Hyrcanian forests 17 in Golestan province. To consider how LULC change scenarios affect GHGs, REDD 18 project was executed in a period of 30 years (2018-2048) at intervals of 5 years. In this 19 regard, study area was divided into the project area and leakage belt based on the Multi 20 Criteria Evaluation (MCE) derived forest suitability map. In the baseline scenario, it was 21 assumed that the trend of past LULC changes will continue. 22

Results: By implementation of the project scenario, some degradation activities were 23 controlled. Project scenario was executed with different project success rates (PSR) of 24 90, 80, 70, 60 and 50\% to examine its efficiency rate in reducing GHGs emissions. 25 According to the results, 38206.8 hectares of forests within the project area will be 26 destroyed by 2047 under the baseline. The destroyed area will be reach $39784.4 \quad 27$ hectares in the leakage belt. The highest rate of forest destruction in the project area 28 will occur in the last 5 years (1352 hectares per year), so the highest $\mathrm{CO}_{2}$ and non- $\mathrm{CO}_{2} \quad 29$ emissions equal to 662655.3 tons/year and $278.94 \mathrm{tCO}_{2} \mathrm{e} /$ year will happen in the last 530 years (2042-2047). Based on the results, reducing the PSR affected the efficiency of the 31 project scenario. The highest and lowest rates of emissions reduction were observed 32 respectively with PSR of 90 and 50\%. 33

Conclusions: That's very important for developing countries especially Iran that are 34 facing many challenging forest conservation decisions. This study innovated in 35 methodology by integrating the MCE into the REDD steps. The MCE as a spatial targeting 36 method could be applied to increase the efficiency of the REDD project, as we illustrated 37 for the case of Hyrcanian forests. 38

Key Words: Deforestation, Land Change Modeler, Multi Criteria Evaluation, 40 Ecosystem Services, IPCC, REDD. 


\section{Background}

Forest ecosystems provide a wide range of multiple ecosystem services (ESs) that are

important for sustaining life on earth and maintaining the integrity of the ecosystems (Bauhus et al., 2010; Gamfeldt et al., 2013; Miura et al., 2015; Mri, 2017; Tolessa et al., 2017). One of the most important forest ESs is climate regulation (Costanza et al., 2017; Chu et al., 2019). On one hand, carbon accumulates through growth of trees into forest growing stock. On the other hand, Land use/land cover (LULC) change activities impact carbon stocks (Vauhkonen and Packalen, 2018). By continuing global forest decline (Köthke et al., 2013), FAO (2010) predicts that the current annual global forest loss is 52 about 13 million hectares. The Intergovernmental Panel on Climate Change's fourth 53 assessment report (IPCC, 2014) estimated that agriculture, forestry and other LULC 54 changes specially deforestation contribute $24 \%$ of global anthropogenic greenhouse 55 gases (GHGs). As between the eras from 1750 to 2011, about $180 \mathrm{PgC}$ was released to 56 the atmosphere due to LULC change, mainly deforestation (IPCC 2014). In the absence of potential land mitigation and adaptation policies, climate change can affects many 58 parts of the environment and multiple ESs (Etemadi et al., 2012).

Therefore, reducing land use related GHGs emissions represents a significant climate change mitigation strategy (Collen et al., 2016). One approach to doing so emerged in 2005, by the Reducing Emissions from Deforestation (RED) program (Pistorius, 2012). The United Nations Framework Convention on Climate Change (UNFCCC) introduced RED as a simple monetary mechanism for reducing forest related carbon emissions in developing countries (UNFCCC, 2005). Over the past few years, the scope of RED mechanism was notably extended and now includes forest degradation (the second D in REDD). Also plus activities including sustainable forest management, conservation of forest carbon stocks, enhancement of forest carbon stocks and safeguard forest non carbon values led to the REDD+ project (Vije, 2015). REDD is a global environmental governance mechanism with the objective to slow and eventually halt deforestation and forest degradation from LULC change in developing countries by providing an economic incentive to keep carbon stored in vegetation and soils (Angelsen and WertzKanounnikoff, 2008; Skutsch and Van Laake, 2008; Angelsen and Brockhaus, 2009; Parker et al., 2009; Arévalo et al., 2020). In recent years, REDD projects have attracted much attention around the world as a policy to regulate climate change on a national and regional scale. So far, many developing countries include Indonesia, Philippines, India, Papua New Guinea, Peru, Vietnam, Cambodia, Tanzania, Zambia, Congo, Bolivia, Panama and Paraguay have joined and implemented the REDD program (Rakatama et al. 2019; Ji and Ranjan, 2019; Bos et al., 2019; Massarella et al., 2018; Guadalupe et al., 2018; Sheng et al., 2016). REDD mechanism requires information on LULC change and carbon emission trends from the past to the present and into the future (Harris et al., 2012; Eastman, 2015; Capitani et al., 2019; Arévalo et al., 2020). Because the emissions of GHGs are known to be strongly influenced by LULC change (Cooper et al., 2020; Hundera et al., 2020), scenario analysis with LULC models can play a major role in providing information to decision makers. By purpose of spatial targeting of REDD 
studies, LULC change models such as Land Change Modeler (LCM), Geomod, CA87 MARCOV and CLUE-S have been used for the LULC changes prediction, specially forest 88 loss trend (Feng et al., 2020; Tang et al., 2020; Parsamehr et al., 2019; Mena et al., 2017; Bununu et al., 2016; Kim, 2010; Hewson et al., 2019; Redowan, 2019). Some models 90 such as LCM that permits the simulation of future scenario is integrated with a REDD 91 steps to determine and model anthropogenic GHGs emission reductions (Bununu et al., 2016). In addition to the importance of LULC change models, to increase the REDD 92 context efficiency, site selection is also one of the success determinants. In other words, REDD as a least cost policy to achieve climate regulation, obviously depends on how and where it is implemented (Blom et al., 2010; Lin et al., 2014; Atela et al., 2014).

Located primarily in the dry zone of the northern hemisphere, Iran comprises about $80 \%$ arid or semi-arid lands and just $8.8 \%$ forest cover (Ministry of Jihad-eAgriculture, 2007). As a natural and ancient forests of the world, northern forests of Iran or Hyrcanian forests (Caspian forests) with an area of about 1.2 million ha (Zahedi Amiri and Zargham, 2015) are belong to the Euro-Siberian biome (Zohary, 1973; Browicz, 1989). The high precipitation and mild climate of the Hyrcanian region facilitates broad-leaved dense forests (Noroozi, 2020). The LULC conversion from Hyrcanian forests into other anthropogenic land uses have been one of the major challenges of recent years (Kelarestaghi and Jafarian Jeloudar, 2011), have posed a decrease in the supply of carbon storage and other ESs (Asadolahi et al., 2018). Golestan province has lost an average of 403,350 ha forests $(0.97 \%$ per year) over the years 1990 to 2010. In total, $19.4 \%$ of forest cover was lost during this period (FA0, 2010). Because of the importance of Hyrcanian forests loss in GHGs emotions in north of Iran, the REDD methodology was implemented as an environmentally friendly policy in Golestan province. The REDD strategy not only promote the forest conservation but also contribute to climate regulation. With these objective in mind, by purpose of spatial targeting the REDD, the LCM and Multi-Criteria Evaluation (MCE) modules in TerrSet software were integrated into project steps. In the following, we focused on how different LULC scenarios affect GHGs emissions reduction.

\section{Material and Methods}

\subsection{Study Area}

Golestan province is located in northeastern Iran and lies between latitudes $36^{\circ} 30^{\prime}$ research location is approximately $20438.3 \mathrm{~km}^{2}$. Due to its location in the northern part of the Alborz Mountains, Golestan is divided into three regions; mountainous, submontane, and flat regions. The dominant LULC of the mountainous region is forest and rangeland. The northern slopes of Alborz Mountains face to one of the main resources of humid air for Iran, Caspian Sea air masses, which have caused formation of dense deciduous forests of the northern slopes. The submontane region includes small

$$
<\text { Fig. } 1>
$$

\subsection{REDD Methodology Steps}


As shown in Fig. 2, REDD methodology, based on the World Bank's Bio-Carbon Fund scenarios (Fund, 2008). In the baseline scenario it was assumed that the trend of past LULC changes especially forest loss will continue, and in the project scenario some of the degradation and deforestation activities were controlled and stopped (Eastman, 2014). The REDD steps are explained in detail in the next sections.

$$
<\text { Fig. 2> }
$$

\subsubsection{Definition of the spatial-temporal boundaries and carbon pools}

In the first step of the REDD project, the temporal boundaries, carbon pools and the 137 spatial boundaries of the reference region, project area and leakage belt are defined (Fund, 2008). The duration of the REDD methodology activity must be at least 20 years change will be obtained, projected into the future and monitored (Fund, 2008). The project activities. In contrast, the leakage belt is the land adjacent to the project area in which baseline activities are likely to be displaced from inside the project area (Fund, 2008). Five carbon pools include above-ground, below-ground, dead wood, litter and is permitted in REDD methodology, Quantities of carbon stocks were provided by the results of reviewing 31 internal studies and IPCC reports (Table 1).

$$
<\text { Table } 1>
$$

Based on Fund (2008), the starting and end dates of the project were considered from the year 2018 to 2048. The boundary of Golestan province was considered as the reference region and the project area and leakage belt boundaries extraction was done using MCE-derived forestry suitability map.

\subsubsection{Generating MCE-derived forest suitability map}

The MCE methodology operates based a series of raster layers of environmental implementing the fuzzy set theory (Zadeh, 1965), factor layers could be fuzzified raster space allow map overlay procedure and acknowledge uncertainty in data layers and also provide a means for compromising between different opinions on the importance of each layer. Before map integration, factor layers are weighted to indicate their relative importance. In this regard, the analytical hierarchy process (AHP) is 
There is also a second category of digital map layers used in the MCE analysis that depict absolutely unsuitable lands for the LULC category under study, called 'constraint' layers, and they retain only 0 and 1 values to indicate impossibility and possibility, respectively, of developing the targeted LULC category (Table 3).

The standardized factor layers and constraint maps are combined via map overlay

Where $\mathrm{W}_{\mathrm{i}}$ stands for the AHP-derived relative weight for factor layer $\mathrm{i}, \mathrm{X}_{\mathrm{i}}$ refers to the standardized (fuzzified) value for layer $i, \Pi$ mirrors the multiplication operator, and finally, $C_{j}$ indicates the constraint $j$. The output of such map overlay analysis is a single raster layer with cell values ranging between $0-255$ (or $0-1$ ), which is based on fuzzification range. Greater scores of suitability imply a higher land potential for the

\subsubsection{Analysis of historical LULC change}

The goal of this step is to collect and analyze spatial data in order to identify current LULC conditions and to analyze LULC change during the historical reference period within the reference region, leakage belt and project area (Fund, 2008). LULC change was calculated using the change analysis tab of the LCM. LULC maps for 1984, 2008 and

\subsubsection{Analysis of agents, drivers and underlying causes of deforestation}

The goal of this step is understanding who is deforesting the forest (the agent) and what drives LULC decisions (drivers and underlying causes) (Fund, 2005). The driver 
from agriculture, (8) distance from rangelands and (9) distance from water resources.

\subsubsection{Projection of the rate and location of future deforestation}

The objective of this step as the core of the baseline scenario in REDD methodology is to locate in space and time the baseline deforestation expected to occur within the simulated map for 2018. By using the historical LULC maps (1984-2008), a collection of conditional probability images, a transition areas matrix, and a Markov transition probabilities matrix were produced. Also, driver variables (section 2.2.3) affecting the trend of the variation from one LULC class to another were added in the LCM as a raster maps. Performance of the model during the calibration process was evaluated using the Kappa index of agreement and the result validated the simulation success of the model (Kappa $>0.80$ ). Confirmation of model outputs at this stage provides the conditions for the implementation of the next step.

2.2.5. Identification of forest classes in the areas that will be deforested under the baseline

The goal of this step is to complete the LULC change component of the baseline 237 scenario by determining the forest classes that would be deforested without project case. The REDD project is usually implemented over a 30 years period and evaluations are carried out over a five years period (Fund, 2005). According to this pattern, changes

\subsubsection{Estimation of baseline carbon stock changes (C-Baseline) and other GHGs emissions}

This step finalizes the baseline scenario assessment by calculating baseline carbon stock changes (C-Baseline) and non- $\mathrm{CO}_{2}$ emissions (Fund, 2005). For calculating the CBaseline, initially, $\mathrm{CO}_{2}$ emissions in forest class at year $t$ is calculated with the below equation:

Where $A B S L_{i c l, t}$ : Area of initial forest class $i c l$ deforested at time $t$ (ha); Ctot $_{i c l, t}$ : (tCO2e).

Furthermore, by converting the forest class to other LULC types, part of the carbon is also deposited in the replaced LULC classes according to the following equation: 255 Sequestrated carbon in the replaced LULC classes $=\sum_{f c l=1}^{F c l} A B S L_{f c l, t} *$ 256 Ctot $_{f c l, t}$ 
Where $A B S L_{f c l, t}$ : Area of the final non-forest class $f_{c l}$ at time $t\left(\right.$ ha); $C t o t_{f c l, t}$ : Average

Finally, the total baseline carbon stock change in the project area and leakage belt at year $t$ is calculated as follows:

$C-$ Baseline $=\sum_{i c l=1}^{I c l} A B S L_{i c l, t} *$ Ctot $_{i c l, t}-\sum_{f c l=1}^{F c l} A B S L_{f c l, t} * \operatorname{Ctot}_{f c l, t}$

Where $\triangle C B S L_{t}$ is Total baseline carbon stock change at year $t(\mathrm{tCO} 2 \mathrm{e})$.

Conversion of forest to non-forest classes by fire is a source of non- $\mathrm{CO}_{2}$ gases 2018.

\subsubsection{Estimation of actual carbon stock changes (C-Actual) and other GHGs emissions under the project scenario} 272

The goal of this step is to provide an actual estimate of carbon stock change under the under project scenario compared to baseline could be indicated as the Project Success Rate (PSR) percentage. The equation for C-Actual calculation is as follows:

$C-$ Actual $=($ The amount of carbon released under baseline $) *(P S R)$

\subsubsection{Estimation of possible leakage due to GHGs emissions associated to leakage (C- Leakage)}

The goal of this step is to provide an ex ante estimate of carbon stock changes and increase in GHGs emissions due to leakage (C-Leakage) (Fund, 2008). It assumed that baseline activities that would be implemented inside the project area in the absence of the project activity could be displaced outside the project boundary due to the implementation of the project scenario. Therefore, leakage rate (LR) is the decrease in carbon stocks and the increase in GHGs emissions attributable to the implementation of the project scenario that occurs outside the boundary of the project area (Fund, 2008) (Eq. 6).

$\mathrm{C}-$ Leakage $=($ The amount of carbon released under baseline $) *(\mathrm{LR})$

\subsubsection{Calculation of net GHGs emission reductions (C-REDD)}

The net anthropogenic GHGs emission reduction of a REDD scenario is calculated as follows:

$\mathrm{C}-\mathrm{REDD}=(\mathrm{C}-$ Baseline $)-(\mathrm{C}-$ Actual $)-(\mathrm{C}-$ Leakage $)$

Where: C-REDD: Net anthropogenic GHGs emission reduction attributable to the 
Due to the importance of PSR and LR factors in GHGs emissions, several REDD

scenarios were determined in this step. In this regard, Efficiency Rate (ER) was defined (Eq. 8). In any scenario, the values of PSR and LR factors were changed and the impact of changes on reducing GHGs emissions were assessed (Table 4).

\subsection{Model sensitivity analysis to changes in forest carbon stocks}

REDD methodology allows the use of carbon stocks estimates in similar ecosystems based on previous studies as well as information contained in IPCC reports (Fund, 2008). In order to sensitivity analysis of the model, the change of the forest carbon stocks was examined in different states. In each state, forest carbon stocks were steadily reduced or increased (Table 5). In the baseline state, the estimated amount of carbon stocks in section 2.2.1 was used. In the other four states, 25 and 50\% were added or reduced to the amount of carbon stocks, respectively (Fig. 3).

$$
\begin{aligned}
& <\text { Fig. } 3> \\
& <\text { Table } 5>
\end{aligned}
$$

\section{Results and Discussion}

\subsection{MCE-derived border of project area and leakage belt}

As shown in Fig. 4.a, the most suitable areas for forestry were mapped by applying the MCE method at a standard 0-255 scale. It could be seen that the southern part of the intensively affected the capabilities of the southern part to develop forests (Mirghaed et al., 2020).

\section{$<$ Fig. 4>}

In this study, we demonstrated how to use a MCE-derived forest suitability map to 319 identify the most suitable areas for project area and leakage belt. Based on the value range of the forest utility map, the amount of 335087.9 ha was allocated to the project area and 203163.7 ha to the leakage belt (Fig. 4.b). Without REDD implementation, 31443.8 ha of forests within project area would be destroyed until 2047 year. In order to prevent of this problem, in the first step of REDD project, greater scores of forest suitability map were allocated to project area and lower scores were assigned to leakage belt. With this approach, more suitable forest areas were conserved as project areas and the leakage belt was the land adjacent to the project area in which destructive activities were likely to be displaced from inside the project area (Fund, 2008).

It should be noted that recent studies such as Modica et al (2016), Valente at al. (2017), Goleiji et al (2017), Hashemi (2018), ollah Hosseini et al (2019), Ezzati (2019) 
makers to conserve the most suitable areas for the carbon storage, climate regulation

and other ESs. Lin et al (2014) and Blom et al (2010) emphasized that both the design

3.2. Analysis of the historical LULC change, deforestation drivers and future deforestation projection

Fig.5a-c show the three classified LULC maps for the analyzed years. The overall accuracy of $0.75,0.78$ and 0.85 showed an almost perfect agreement for the classified maps of 1984, 2008 and 2018, respectively.

Change detection analyses between 1984 to 2018 was conducted in two sub periods including 1984-2008 and 2008-2018. In the year 1984, forest, rangeland and later date tested, as by this time rangeland was no longer the dominant LULC class, having been replaced by agriculture.

From 1984 to 2018, forest, one of the most prevalent classes was largely converted (more than $\left.1000 \mathrm{~km}^{2}\right)$ as the areal coverage of forest decreased $26.5 \%\left(5382 \mathrm{~km}_{2}\right)$ at the cost of agriculture and rangeland increase to $34.0 \%\left(6887 \mathrm{~km}^{2}\right)$ and $33.0 \%(6701$ $\mathrm{km}^{2}$ ) of the study area respectively. Furthermore during these years, about $182 \mathrm{~km}^{2}$ of 360 study area were mainly converted into human made class. Over the whole period (1984-2018), water bodies and human made areas covered the smallest areas. Comparing the two sub periods (1984-2008 and 2008-2018), the forest changes follow a similar decreasing trend (Table 6). Although the deforestation rate is somewhat 363 slower in the second period $(-2.1 \% /-2.8 \%)$. This problem showed that during the second sub period (2008-2018), deforestation has not only occurred at the expense of 365 agriculture, but the other LULC classes have also grown. In contrast to the first period, rangeland increased with positive growth rate $(+0.9 \% /-0.19 \%)$.

Steps 3 to 5 were performed with LCM module in TerrSet software. In the baseline 368 scenario was assumed the continuation of deforestation change rates over the past years (1984-2018) in the reference region, project area and leakage belt. Variables include slope, elevation, distance from rangelands, distance from croplands, distance from human made areas, distance from forest edges, distance from roads and distance from rivers were significantly correlated with deforestation during 1984-2002 (Cramer values $>0.11$ ) and used as explanatory variables for projection of the rate and location of future deforestation (Fig.6).

The variables slope, elevation and distance from rangeland were the most significant 
"aspect". This means that this variable had low significance in deforestation prediction. watershed, Shooshtari et al (2020) in the Ghara-su basin and Zabihi et al (2020) in in the Talar watershed, northern Iran.

After selecting explanatory variables the transition sub models were defined and

For projection of future deforestation under the baseline scenario, in addition to transition probability matrix for the years 1984 and 2008. According to the results, the highest likelihood of transition was from forest class to agriculture and rangeland.

The quantity of changes extracted from the Markov chain (Table 8) and transition 396 potential layers used to predict future LULC. In this step, the 1984 and 2008 LULC maps were used as an observed data for calibration of LCM. Also the actual LULC map for the year 2018 was used to verify the simulated map of 2018. This was achieved by running the VALIDATE module (Pontius, 2000). The Kappa statistics value (0.82) showed that include 2022, 2027, 2032, 2037, 2042 and 2047.

403

Fig. 8 shows the extent of deforestation in the project area and leakage belt. The 404 highest rate of forest destruction in the project area occurred in the last 5 years, which 406 is 1352 hectares. While the most destruction in the leakage belt was 1435 hectares and 407 occurred in the first 5 years. The destroyed area reaches 33548.8 hectares in the leakage belt.

$$
<\text { Fig. } 8>
$$

A major component of the REDD project is historical change assessment specially deforestation and the underlying causes of changes (Eastman, 2015). As studies on LULC change analysis in north of Iran showed that Hyrcanian forests were the main contributor to increase agriculture (Minaei and Kainz, 2016; Asadolahi et al., 2018; Nasiri et al., 2019; Aghsaei et al., 2020; Shooshtari et al, 2020). Studies in other parts of the world also confirm that deforestation has taken place at the expense of agricultural activities (Fernandes et al., 2020). In Golestan province like other areas in northern Iran, most of deforestation was occurred surrounding forest areas (Shooshtari and Gholamalifard, 2015; Asadolahi et al., 2018; Beygi Heidarlou et al., 2019) at the expense of marginal expansion of agricultural lands to meet local stakeholder interests. Although 
residents. Also Poorzadi and Bakhtiari (2009) identified illegal logging, floods and the

cultivating lands expansion by local stakeholders as a main reasons of the loss of Iran's

Caspian forests. Consistent with the results of this study, the studies of Heidarlou et al (2019) and Jahanifar et al (2020) highlighted that unsustainable land use policies over the past decades have led to forest degradation more severely in Iran.

\subsection{Estimation of C-Baseline and other GHGs emissions under baseline scenario}

Fig. 9 shows $\mathrm{CO}_{2}$ emission rate within the project area under the baseline scenario. due to deforestation and net $\mathrm{CO}_{2}$ emission after carbon sequestration within the leakage

The conversion of forests to other LULC types by fire is an important source of other to $278.94 \mathrm{tCO}_{2} \mathrm{e}$ within the project area occurred in the last 5 years (2042-2047). Also, in the first 5 years at the rate of $296.07 \mathrm{tCO}_{2} \mathrm{e}$ and the lowest rate was $257.18 \mathrm{tCO}_{2} \mathrm{e}$ in the last 5 years. The result of the REDD implementation confirmed that baseline scenario was not appropriate policy as the continuation of current LULC changes without any land planning strategy would led to more GHGs emissions. The results year 2047, a total of 21386238,22269266 and 43655742 tons of $\mathrm{CO}_{2}$ would be emitted from the project area, leakage belt and the whole area, respectively. The estimated rates show the vital role of Hyrcanian forests in reducing GHGs emissions. This observation is regard Zarandian et al (2017) showed that among the possible LULC future scenarios, the BAU scenario had the most negative reduction effect on multiple ESs specially carbon storage.

Another positive point in this study was the involvement of fire related destructive processes. Forest fire information of Golestan province showed that since the year 2011 to 2018, 1511 fires have occurred, destroying about 1501 hectares of the Golestan 


\subsection{Estimation of C-Actual, C-Leakage, C-REDD and other GHGs emissions under the} different project scenarios

Figs. 11 and 12 show the C-Actual and non- $\mathrm{CO}_{2}$ emissions within the project area under different REDD project scenarios. With the implementation of the first scenario, the $\mathrm{CO}_{2}$ emission within the project area was estimated at 57396.82 tons in the year 2018. This rate reached to 66265.59 tons in the year 2047. On the other hand, non- $\mathrm{CO}_{2}$ emissions were estimated at $24 \mathrm{tCO}_{2} \mathrm{e}$ and $27.8 \mathrm{tCO}_{2} \mathrm{e}$ respectively. In the second scenario, PSR dropped from 90 to $80 \%$ which led to a change in GHGs emissions. Accordingly, the $\mathrm{CO}_{2}$ emission within the project area was estimated at 114793.6 tons in the year 2018. This rate in 2047 reached to 132531.2 tons. Non- $\mathrm{CO}_{2}$ emissions were estimated at $48 \mathrm{tCO}_{2} \mathrm{e}$ and $55.7 \mathrm{tCO}_{2} \mathrm{e}$ respectively. The PSR was considered $70 \%$ in the third scenario. According to the third scenario, $\mathrm{CO}_{2}$ emissions in the years 2018 and 2047 within the project area were estimated at 172190.05 and 198796.8 tons, respectively and non- $\mathrm{CO}_{2}$ emissions were estimated at $72.01 \mathrm{tCO} e$ and $83.6 \mathrm{tCO} e$. Reducing the PSR affects the EC of the project. The EC in the first, second and third scenarios was 80, 60 and $40 \%$, respectively. In the fourth scenario, this coefficient reached to $20 \%$. Reducing the EC by $20 \%$ brought GHGs emissions closer to the baseline scenario. According to the fourth scenario, $\mathrm{CO}_{2}$ emissions in the years 2018 and 2047 within the project area were estimated at 229587.3 and 265062.3 tons, respectively. Non- $\mathrm{CO}_{2}$ emissions were estimated at 96.0 tCO2e and 111.57 tCO2e. The fifth scenario, with the lowest PSR (50\%), was the closest scenario to the baseline. According to this scenario, $\mathrm{CO}_{2}$ emissions in the years 2018 and 2047 in the project area were estimated at 286984.1 and 331327.9 tons, respectively. Non-CO2 emissions were estimated at 120 tCO2e and 139.4 tCO2e.

$$
\begin{aligned}
& <\text { Fig. } 11> \\
& <\text { Fig. 12> }
\end{aligned}
$$

Increase in the GHGs emissions within leakage belt was estimated by displacing the scenarios. Leakage rates in the first to fifth scenarios were 10, 20, 30, 40 and 50\%, respectively. $\mathrm{CO}_{2}$ emissions within leakage belt in the fifth scenario, which had the highest leakage rate, was higher than other scenarios. The maximum $\mathrm{CO}_{2}$ emission pattern of non- $\mathrm{CO}_{2}$ GHGs in the leakage belt was very similar to C-leakage emissions. The highest emission was in the year 2047 in the fifth scenario with 139.4 tCO2e

As shown in Fig. 13, C-REDD was estimated from equation (7) under different project

The goal of developing less successful REDD project scenarios was to assess the 503 impact of the unsustainable land use policies. As inappropriate decision making 504 approaches reduced the success rate of the REDD project up to the baseline scenario. 
(2019) revealed that in spite of the implementation of preservation policies, forest loss 508 in Iranian Sardasht Zagros forest hasn't decreased. They attributed the inefficiency of 509 conservation policies to the poor implementation practices, lack of fund, lack of local 510 resident's participation in management, unemployment and the lack of use the modern technologies in the future. In contrast, studies from Madagascar and Brazil that 512 conducted by Hewson et al (2019) and Sanquetta et al (2020), have shown that 513 effective forest conservation policies could deliver substantial GHGs emissions reduction.

$$
\begin{aligned}
& \text { < Fig. 13> } \\
& \text { < Fig. 14> }
\end{aligned}
$$

\subsection{Model sensitivity analysis to changes in forest carbon stocks}

However, the use of carbon estimates of previous studies is permitted in REDD 519 methodology, but probable changes in the carbon stocks was investigated in different 520 states by executing sensitivity analysis. According to results, as carbon storage increased to $50 \%, \mathrm{CO}_{2}$ emissions dropped to 719797 tons by the year 2047. On the other hand, $50 \%$ reduction in carbon storage reduced $\mathrm{CO}_{2}$ emissions to 198551 tons by the year 2047, the lowest emission among possible states (Fig. 15). The reduction in non- $\mathrm{CO}_{2}$ GHGs emissions in the second state was the lowest at the year 2047. The rate of this decrease was about 334.7 tCO2e (Fig. 16).

\section{Conclusions}

$<$ Fig. 16>

528

This paper presented an example of future scenario planning to reduce GHGs 530 emissions in Iran's Hyrcanian forests. According to Hewson et al (2019) scenario 531 analysis can support policy decisions by demonstrating potential impacts of policies on 532 future deforestation and $\mathrm{GHG}_{\mathrm{s}}$ emissions. That's very important for developing 533 countries especially Iran that are facing many challenging forest conservation decisions. Also this study innovated in methodology by integrating the MCE into the REDD steps. The MCE as a spatial targeting method could be applied to increase the efficiency of the REDD project, as we illustrated for the case of Hyrcanian forests. Our approach in using the spatially explicit models such as LCM, MCE and REDD have the potential to notify

The work is supported by Iran National Science Foundation (INSF), grant number 97013103. 
Land Change Modeler (LCM)

References

Aghsaei, H., Dinan, N.M., Moridi, A., Asadolahi, Z., Delavar, M., Fohrer, N. and Wagner, 555 P.D., 2020. Effects of dynamic land use/land cover change on water resources and 556 sediment yield in the Anzali wetland catchment, Gilan, Iran. Science of The Total 557 Environment, 712, p.136449. 558

Angelsen, A. and Wertz-Kanounnikoff, S., 2008. What are the key design issues for 559 REDD and the criteria for assessing options. Moving ahead with REDD: issues, options 560 and implications. CIFOR, Bogor, Indonesia. $\quad 561$

Angelsen, A., and Brockhaus, M., 2009. Realising REDD+: national strategy and policy 562 options. Centre for International Forestry Research, Bogor, Indonesia. 563

Asadolahi, Z., Salmanmahiny, A. and Sakieh, Y., 2017. Hyrcanian forests conservation 564 based on ecosystem services approach. Environmental Earth Sciences, 76(10), p.365. 565

Asadolahi, Z., Salmanmahiny, A., Sakieh, Y., Mirkarimi, S.H., Baral, H. and Azimi, M., 566 2018. Dynamic trade-off analysis of multiple ecosystem services under land use change 567 scenarios: Towards putting ecosystem services into planning in Iran. Ecological 568 Complexity, 36, pp.250-260.

Atela, J.O., Quinn, C.H. and Minang, P.A., 2014. Are REDD projects pro-poor in their spatial targeting? Evidence from Kenya. Applied Geography, 52, pp.14-24.

Heidarlou, H.B., Shafiei, A.B., Erfanian, M., Tayyebi, A. and Alijanpour, A., 2019. Effects of preservation policy on land use changes in Iranian Northern Zagros forests. Land Use Policy, 81, pp.76-90.

Blom, B., Sunderland, T. and Murdiyarso, D., 2010. Getting REDD to work locally: 574 lessons learned from integrated conservation and development projects. Environmental science \& policy, 13(2), pp.164-172.

575

576

Bos, A.B., De Sy, V., Duchelle, A.E., Herold, M., Martius, C. and Tsendbazar, N.E., 2019. Global data and tools for local forest cover loss and REDD+ performance assessment: Accuracy, uncertainty, complementarity and impact. International Journal of Applied 580 Earth Observation and Geoinformation, 80, pp.295-311.

Browicz, K. 1989. Chorology of the Euxinian and Hyrcanian element in the woody flora of Asia. Plant Syst Ev.ol, 162(1), pp.305-314.

Capitani, C., Van Soesbergen, A., Mukama, K., Malugu, I., Mbilinyi, B., Chamuya, N., Kempen, B., Malimbwi, R., Mant, R., Munishi, P. and Njana, M.A., 2019. Scenarios of land use and land cover change and their multiple impacts on natural capital in Tanzania. Environmental conservation, 46(1), pp.17-24.

Chu, X., Zhan, J., Li, Z., Zhang, F. and Qi, W., 2019. Assessment on forest carbon sequestration in the Three-North Shelterbelt Program region, China. Journal of Cleaner Production, 215, pp.382-389.

584

585

586

Collen, W., Krause, T., Mundaca, L. and Nicholas, K.A., 2016. Building local institutions 
Cooper, H.V., Evers, S., Aplin, P., Crout, N., Dahalan, M.P.B. and Sjogersten, S., 2020.

Greenhouse gas emissions resulting from conversion of peat swamp forest to oil palm plantation. Nature Communications, 11(1), pp.1-8.

Costanza, R., De Groot, R., Braat, L., Kubiszewski, I., Fioramonti, L., Sutton, P., Farber,

Eastman, J.R., 2009. Idrisi Taiga. Worcester, MA: Clark University.

Etemadi, H., Samadi, S.Z. and Sharifikia, M., 2012. Statistical downscaling of climatic variables in Shadegan Wetland Iran. Earth Sci Clim Chang, 1, p.508.

601

Ezzati, S., 2019. Geospatial multicriteria decision analysis in forest operational planning. In Spatial Modeling in GIS and $R$ for Earth and Environmental Sciences (pp. 85-116). Elsevier.

FAO. (2010), Global Forest Resources Assessment 2010: Main report, Rome, Italy.

Fernandes, M.M., de Moura Fernandes, M.R., Garcia, J.R., Matricardi, E.A.T., de 606 Almeida, A.Q., Pinto, A.S., Menezes, R.S.C., de Jesus Silva, A. and de Souza Lima, A.H., 2020. Assessment of land use and land cover changes and valuation of carbon stocks in the Sergipe semiarid region, Brazil: 1992-2030. Land Use Policy, 99, p.104795.

Fund, B., 2008. Methodology for Estimating Reductions of GHG emissions from Mosaic Deforestation. RED-NM-001, version, 1.

Gamfeldt, L. et al. Higher levels of multiple ecosystem services are found in forests with more tree species. Nat. Commun. 4, 1340 (2013).

Ghobadi, G.J., Gholizadeh, B. and Dashliburun, O.M., 2012. Forest fire risk zone mapping from geographic information system in Northern Forests of Iran (Case study, Golestan province). International Journal of Agriculture and Crop Sciences, 4(12), pp.818-824.

Goleiji, E., Hosseini, S.M., Khorasani, N. and Monavari, S.M., 2017. Forest fire risk assessment-an integrated approach based on multicriteria evaluation. Environmental monitoring and assessment, 189(12), p.612.

Golestan Province Land use Planning Report. 2013. Published by Gorgan University of Agriculture and Natural Resources, edited by Abdolrassoul Salmanmahiny. Gorgan City, Iran.

Guadalupe, V., Sotta, E.D., Santos, V.F., Aguiar, L.J.G., Vieira, M., de Oliveira, C.P. and Siqueira, J.V.N., 2018. REDD+ implementation in a high forest low deforestation area: Constraints on monitoring forest carbon emissions. Land Use Policy, 76, pp.414-421.

Harris, N.L., Brown, S., Hagen, S.C., Saatchi, S.S., Petrova, S., Salas, W., Hansen, M.C., Potapov, P.V. and Lotsch, A., 2012. Baseline map of carbon emissions from deforestation in tropical regions. Science, 336(6088), pp.1573-1576.

Hashemi, S.A., 2018. Ecological capability evaluation for afforestation and forest expansion using Geographic Information System (GIS) in management area of Caspian Sea. Anais da Academia Brasileira de Ciências, 90(4), pp.3761-3768.

Hewson, J., Razafimanahaka, J.H., Wright, T.M., Mandimbiniaina, R., Mulligan, M., Jones, J.P., Van Soesbergen, A., Andriamananjara, A., Tabor, K., Rasolohery, A. and Razakamanarivo, H., 2019. Land change modelling to inform strategic decisions on

608 609 610 611 612 613 614 615 616 617 618 619 620 621 622 623 624 625 626 627 628 629 630 631 632 633 634 635 636 
Forest cover and CO 2 emissions in eastern Madagascar. Environmental conservation, 637 46(1), pp.25-33.

Hundera, H., Mpandeli, S. and Bantider, A., 2020. Spatiotemporal Analysis of Land-use 639 and Land-cover Dynamics of Adama District, Ethiopia and Its Implication to Greenhouse 640 Gas Emissions. Integrated environmental assessment and management, 16(1), pp.90102.

IPCC. (2014). In Core Writing Team, R. K. Pachauri, \& L. A. Meyer (Eds.), Climate change 2014: Synthesis report. Contribution of working groups I, II and III to the fifth assessment report of the intergovernmental panel on climate change. Geneva: IPCC 151 pp. IPCC.

Jahanifar, K., Amirnejad, H., Mojaverian, S.M. and Azadi, H., 2020. Land use change drivers in the Hyrcanian Vegetation Area: Dynamic simultaneous equations system with panel data approach. Land Use Policy, 99, p.104954.

Ji, Y. and Ranjan, R., 2019. A global climate-economy model including the REDD option. Journal of environmental management, 247, pp.342-355.

Kthke, M., Leischner, B., \& Elsasser, P. (2013), Uniform global deforestation patterns - An empirical analysis, Forest Policy and Economics, 28, 23-37.

Li, H., Ma, Z., Zhu, Y., Liu, Y. and Yang, X., 2020. Planning and prioritizing forest landscape restoration within megacities using the ordered weighted averaging operator. Ecological Indicators, 116, p.106499.

Lin, L., Sills, E. and Cheshire, H., 2014. Targeting areas for reducing emissions from deforestation and forest degradation (REDD+) projects in Tanzania. Global Environmental Change, 24, pp.277-286.

Mahiny, A.S. and Clarke, K.C., 2012. Guiding SLEUTH land-use/land-cover change modeling using multicriteria evaluation: towards dynamic sustainable land-use planning. Environment and planning B: planning and design, 39(5), pp.925-944.

Makhdoum, F.M., 2007. Fundamental of land use planning. University of Tehran press, Tehran

Mas, J.F., Kolb, M., Paegelow, M., Olmedo, M.T.C. and Houet, T., 2014. Inductive pattern-based land use/cover change models: A comparison of four software packages. Environmental Modelling \& Software, 51, pp.94-111.

Massarella, K., Sallu, S.M., Ensor, J.E. and Marchant, R., 2018. REDD+, hype, hope and disappointment: The dynamics of expectations in conservation and development pilot projects. World Development, 109, pp.375-385.

Ministry of Jihad-e-Agriculture, 2007. National Strategy and Action Plan on Drought Preparedness, Management and Mitigation in the Agriculture Sector, Final report TCP/IRA/3003, Deputy Ministry of Agronomic Affair, Tehran, I.R. Iran.

Mirghaed, F.A., Mohammadzadeh, M., Salmanmahiny, A. and Mirkarimi, S.H., 2020. Decision scenarios using ecosystem services for land allocation optimization across Gharehsoo watershed in northern Iran. Ecological Indicators, 117, p.106645.

Miura, S. et al. Protective functions and ecosystem services of global forests in the past quarter-century. For. Ecol. Manag. 352, 35-46 (2015).

641

642

643

644

645

646

647

648

649

650

651

652

653

654

655

656

657

658

659

660

661

662

663

664

665

666

667

668

669

670

671

672

673

674

675

676

677

678 
Modica, G., Pollino, M., Lanucara, S., La Porta, L., Pellicone, G., Di Fazio, S. and Fichera,

C.R., 2016, July. Land suitability evaluation for agro-forestry: definition of a web-based multi-criteria spatial decision support system (MC-SDSS): preliminary results. In Springer, Cham.

Minaei, M. and Kainz, W., 2016. Watershed land cover/land use mapping using 684 remote sensing and data mining in Gorganrood, Iran. ISPRS International Journal of Geo-Information, 5(5), p.57.

Mori, A.S., 2017. Biodiversity and ecosystem services in forests: management and 686 restoration founded on ecological theory. Journal of Applied Ecology, 54(1), pp.7-11.

Nasiri, V., Darvishsefat, A.A., Rafiee, R., Shirvany, A. and Hemat, M.A., 2019. Land use 688 change modeling through an integrated multi-layer perceptron neural network and 689 Markov chain analysis (case study: Arasbaran region, Iran). Journal of Forestry Research, 30(3), pp.943-957.

Noroozi, J., 2020. Plant Biogeography and Vegetation of High Mountains of Central and South-West Asia.

ollah Hosseini, S.A., Moghadasi, P. and Fallah, A., 2019. Forest Road Network Design based on Multipurpose Forestry Management in Hyrcanian Forest. Journal of Environmental Science and Management, 22(2).

Parker, C., Mitchell, A., Trivedi, M. and Mardas, N., 2008. The little REDD book: a guide to governmental and non-governmental proposals for reducing emissions from deforestation and degradation. The little REDD book: a guide to governmental and nongovernmental proposals for reducing emissions from deforestation and degradation.

Parsamehr, K., Gholamalifard, M. and Kooch, Y., 2019. Comparing three transition potential modeling for identifying suitable sites for REDD+ projects. Spatial Information Research, pp.1-13.

Pistorius, T., 2012. From RED to REDD+: the evolution of a forest-based mitigation approach for developing countries. Current Opinion in Environmental Sustainability, 4(6), pp.638-645.

Poorzady, M. and Bakhtiari, F., 2009. Spatial and temporal changes of Hyrcanian forest in Iran. iForest-Biogeosciences and Forestry, 2(5), p.198.

Redowan, M., 2019. Mapping forest dynamics in Bangladesh from satellite images: Implications for the global REDD+ program.

Saaty, T.L., 1980. The Analytic Hierarchy Process: Planning, Priority Setting, Resource Allocation. New York: McGraw Hill.

Sanquetta, C., Dalla Corte, A.P., Sanquetta, M., Pelissari, A. and Tomé, M., 2020. Greenhouse gas emissions due to land use change in Brazil from 1990 to 2015: comparison of methodological approaches. Desenvolvimento e Meio Ambiente, 53.

Sheng, J., Han, X., Zhou, H. and Miao, Z., 2016. Effects of corruption on performance: Evidence from the UN-REDD Programme. Land Use Policy, 59, pp.344-350.

Shooshtari, S.J. and Gholamalifard, M., 2015. Scenario-based land cover change modeling and its implications for landscape pattern analysis in the Neka Watershed, Iran. Remote Sensing Applications: Society and Environment, 1, pp.1-19.

690

691

692

693

694

695

696

697

698

699

700

701

702

703

704

705

706

707

708

709

710

711

712

713

714

715

716

717

718

719

720

721 
Shooshtari, S.J., Silva, T., Namin, B.R. and Shayesteh, K., 2020. Land Use and Cover

Skutsch, M. and Van Laake, P.E., 2008. Redd as multi-level governance in-the-making.

Tang, X., Hutyra, L.R., Arévalo, P., Baccini, A., Woodcock, C.E. and Olofsson, P., 2020.

Tolessa, T., Senbeta, F. and Kidane, M., 2017. The impact of land use/land cover

Valente, R.A., Petean, F.C.D.S. and Vettorazzi, C.A., 2017. Multicriteria decision

Vauhkonen, J. and Packalen, T., 2018. Uncertainties related to climate change and

U.N.F.C.C.C., 2005. Reducing emissions from deforestation in developing countries:

Zabihi, M., Moradi, H., Gholamalifard, M., Khaledi Darvishan, A. and Fürst, C., 2020. 741 Landscape Management through Change Processes Monitoring in Iran. Sustainability, 742 12(5), p.1753.

Zahedi Amiri, Gh. And Zargham, N., 2015. Carbon Sequestration in Terrestrial

Zadeh, L.A., 1965. Fuzzy sets. Information and Control, 8(3), pp.338-353.

Zarandian, A., Baral, H., Stork, N.E., Ling, M.A., Yavari, A.R., Jafari, H.R. and Amirnejad, pp.487-500.

Zohary, M. 1973. Geobotanical foundations of the Middle East 2. Gustav Fischer, 751 Stuttgar. 
Ethics approval and consent to participate: Not applicable

Consent for publication: Not applicable

Availability of data and materials: The datasets used or analysed during the current 758 study are available from the corresponding author on reasonable request.

Competing interests: The authors declare that they have no competing interests.

Funding: The work is supported by Iran National Science Foundation (INSF), grant 761 number 97013103.

Authors' contributions: All authors read and approved the final manuscript. 
Figures

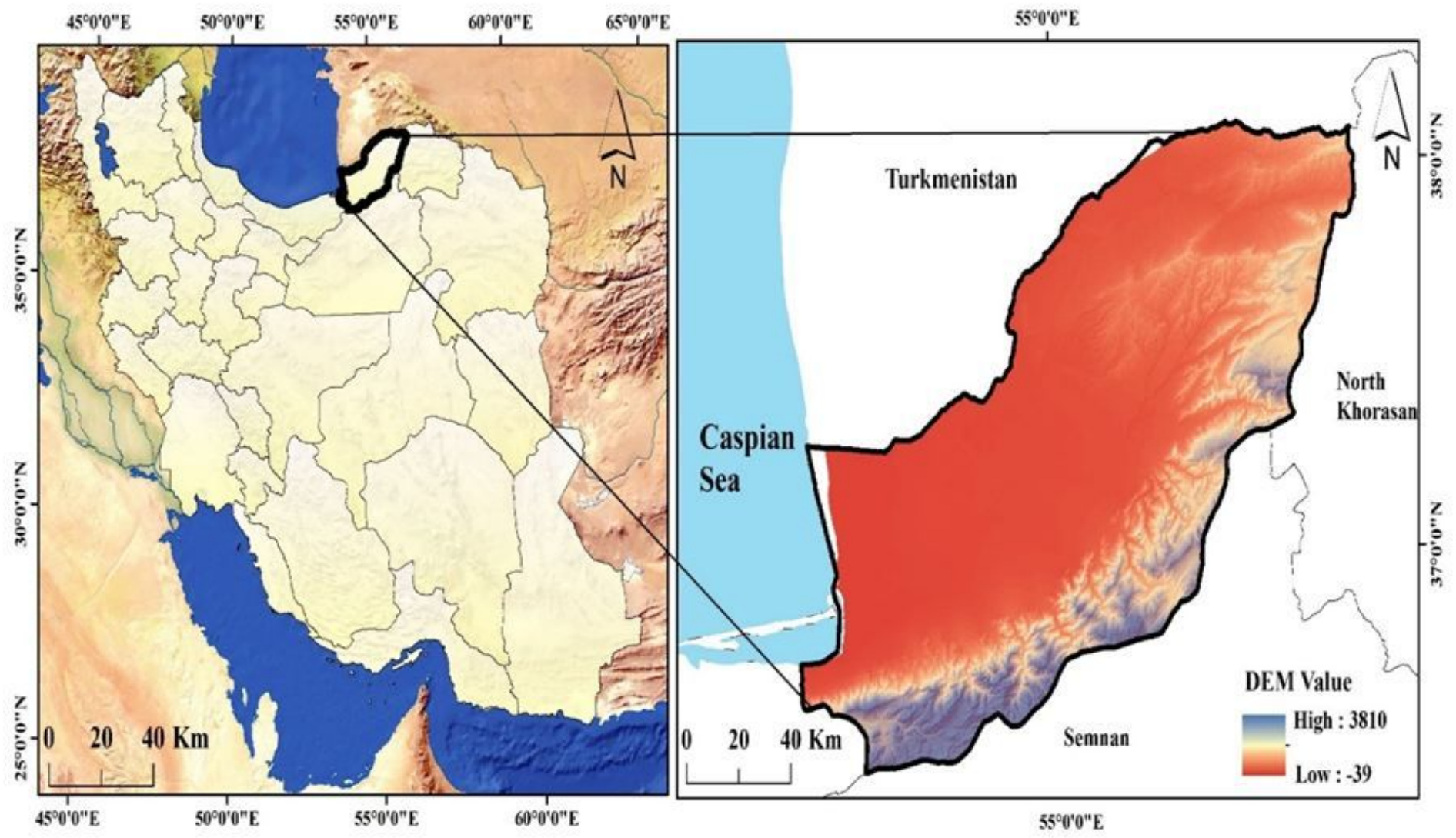

Figure 1

Geographic location of Golestan Province 


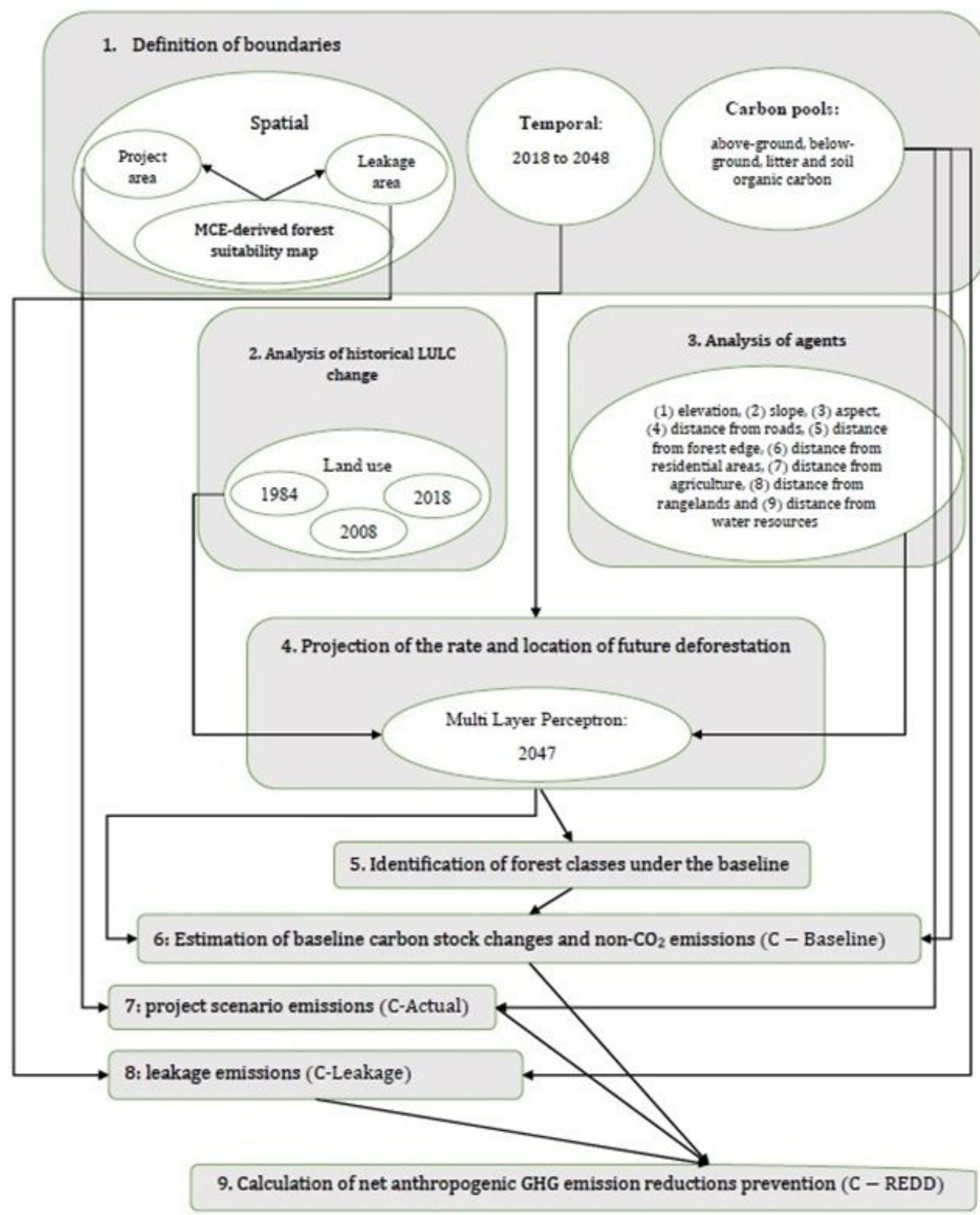

Figure 2

REDD Methodology Steps 


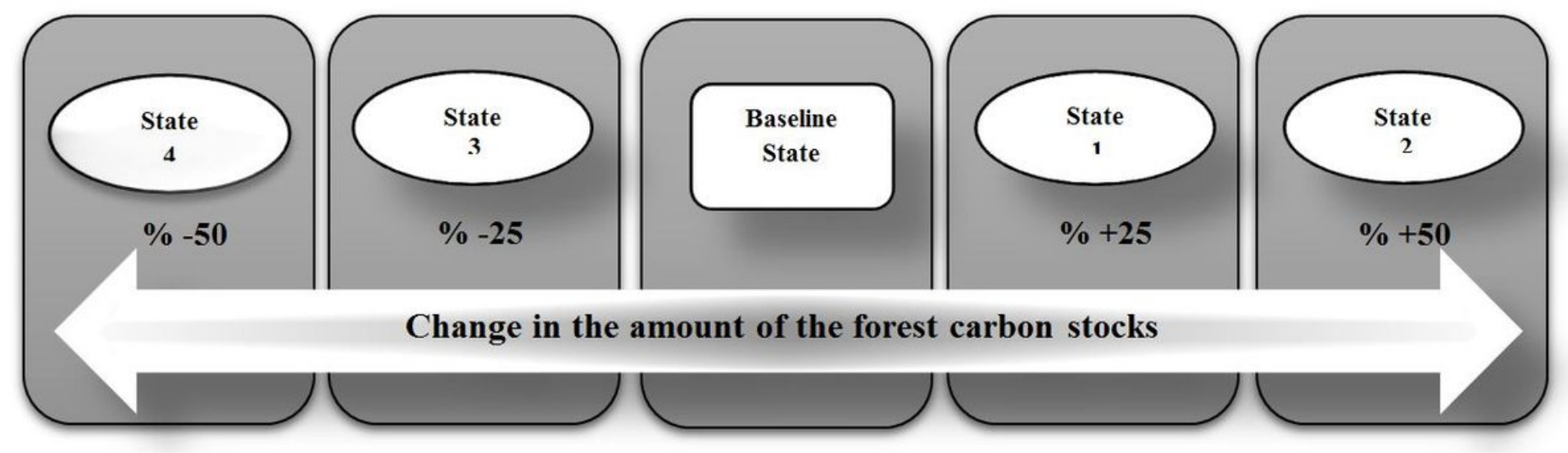

Figure 3

Changes in forest carbon stocks coefficients under different states

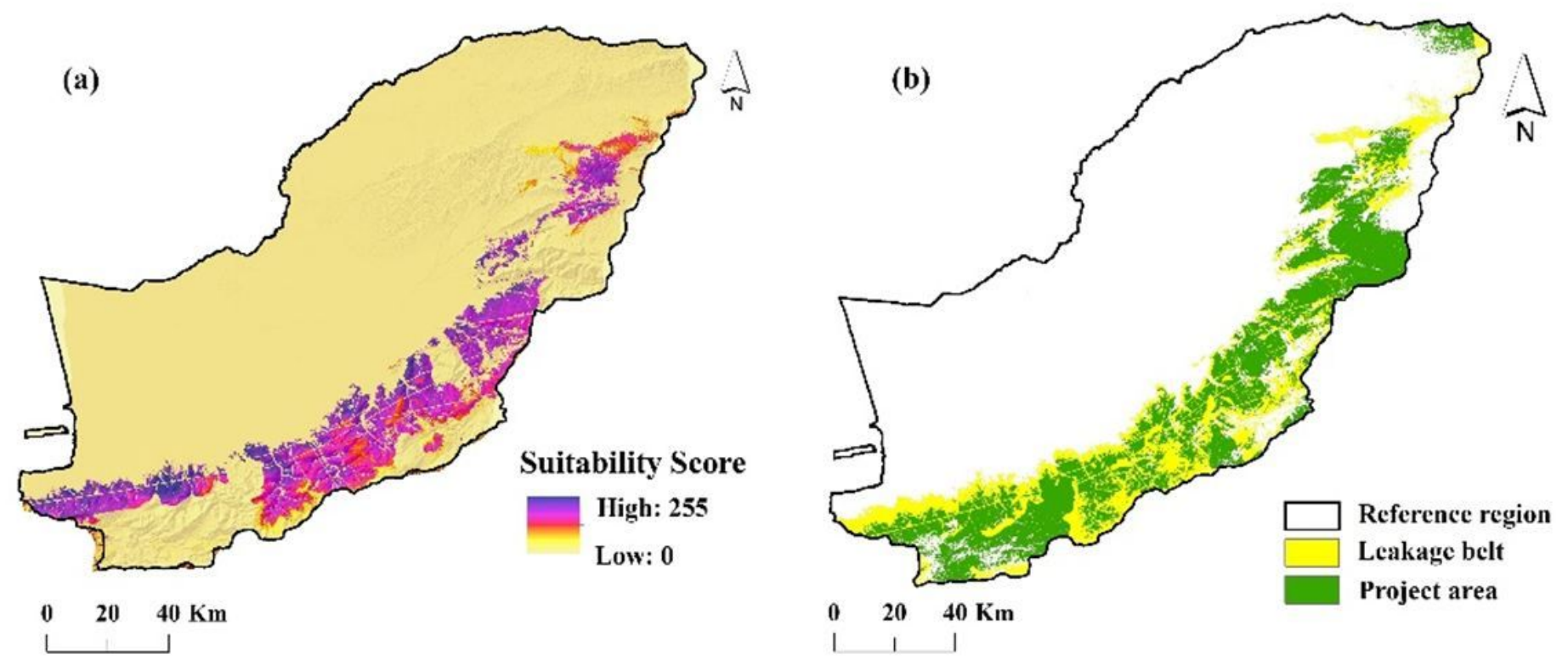

Figure 4

(a) MCE-derived forest suitability map, (b) border of Reference region, project area and leakage belt. 
Aspect

1984

(a)

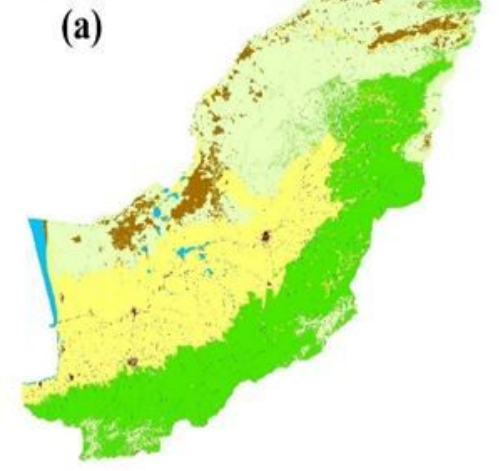

Elevation

2008

(b)

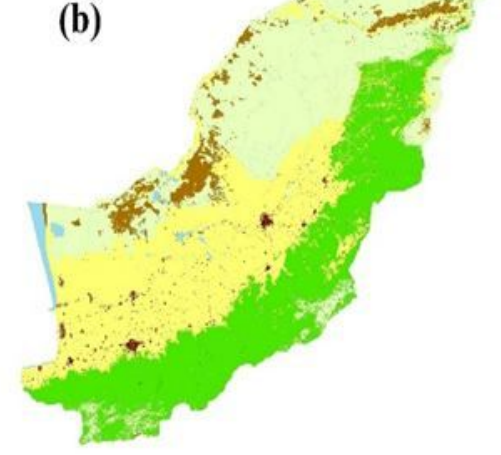

Distance from Agriculture

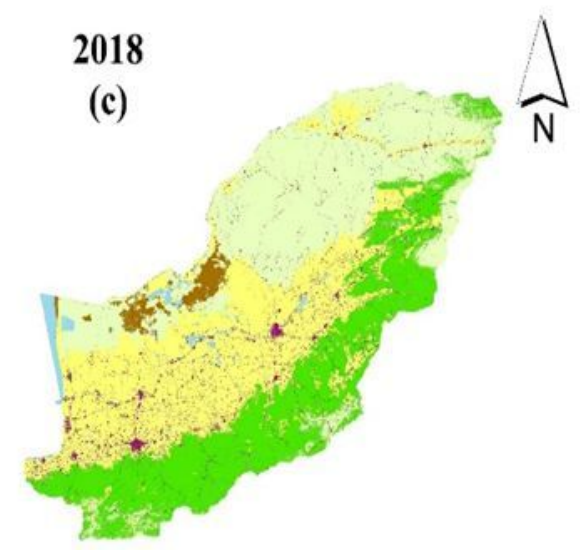

Legend

Human made

Forest

$\square$ Rangeland

Agriculture

Water

Bareland

\section{Figure 5}

LULC maps of study area for (a) 1984, (b) 2008, and (c) 2018 


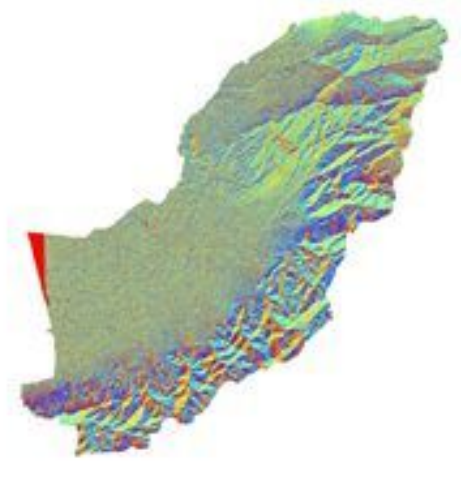

Distance from Roads

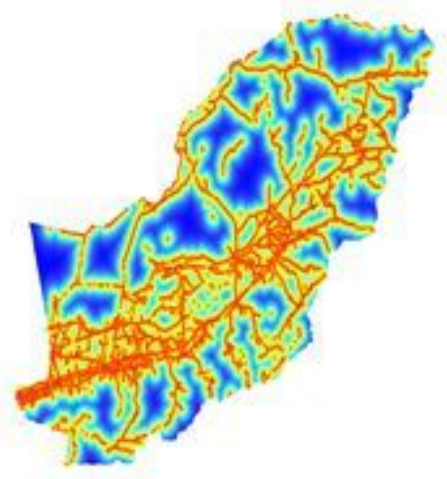

Distance from Human Made

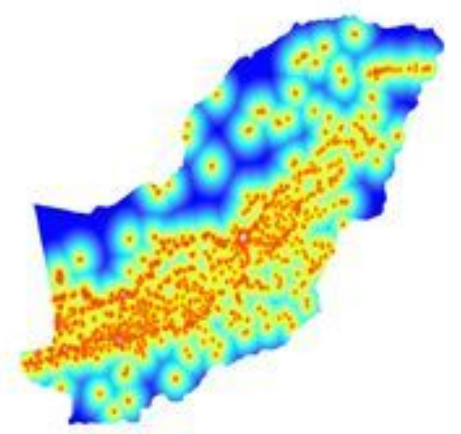

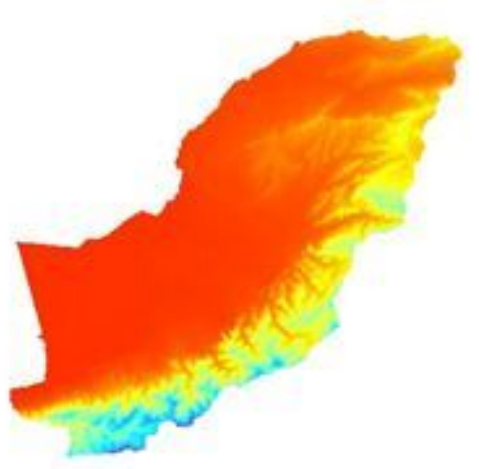
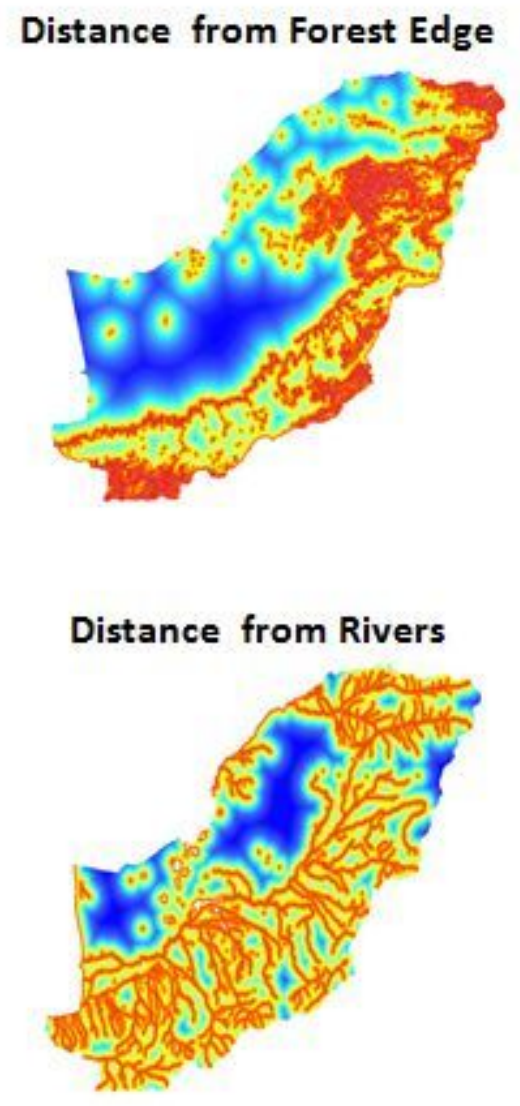

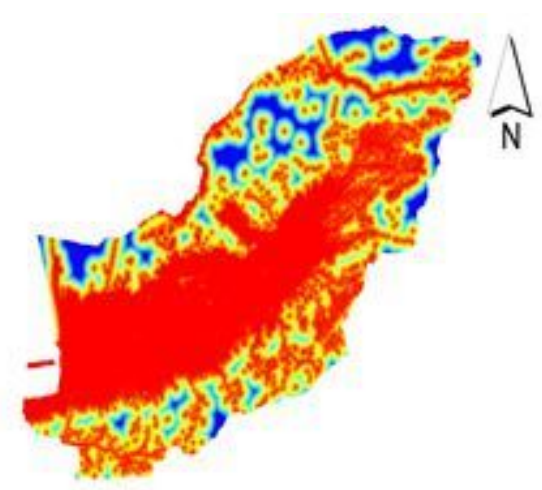

Distance from Rangeland

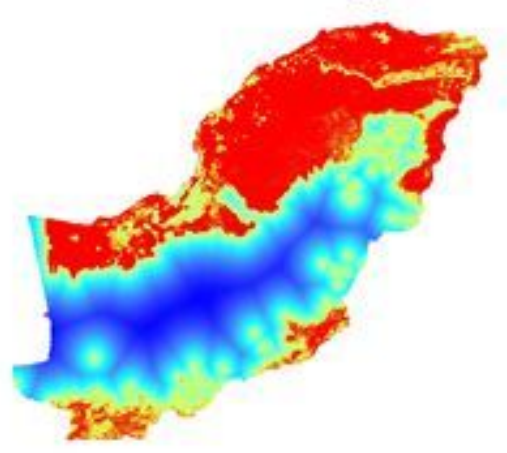

Slope

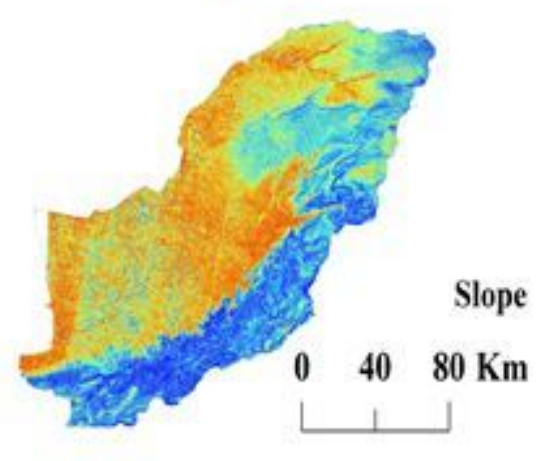

Figure 6

Driver variables correlated with deforestation during 1984-2002 

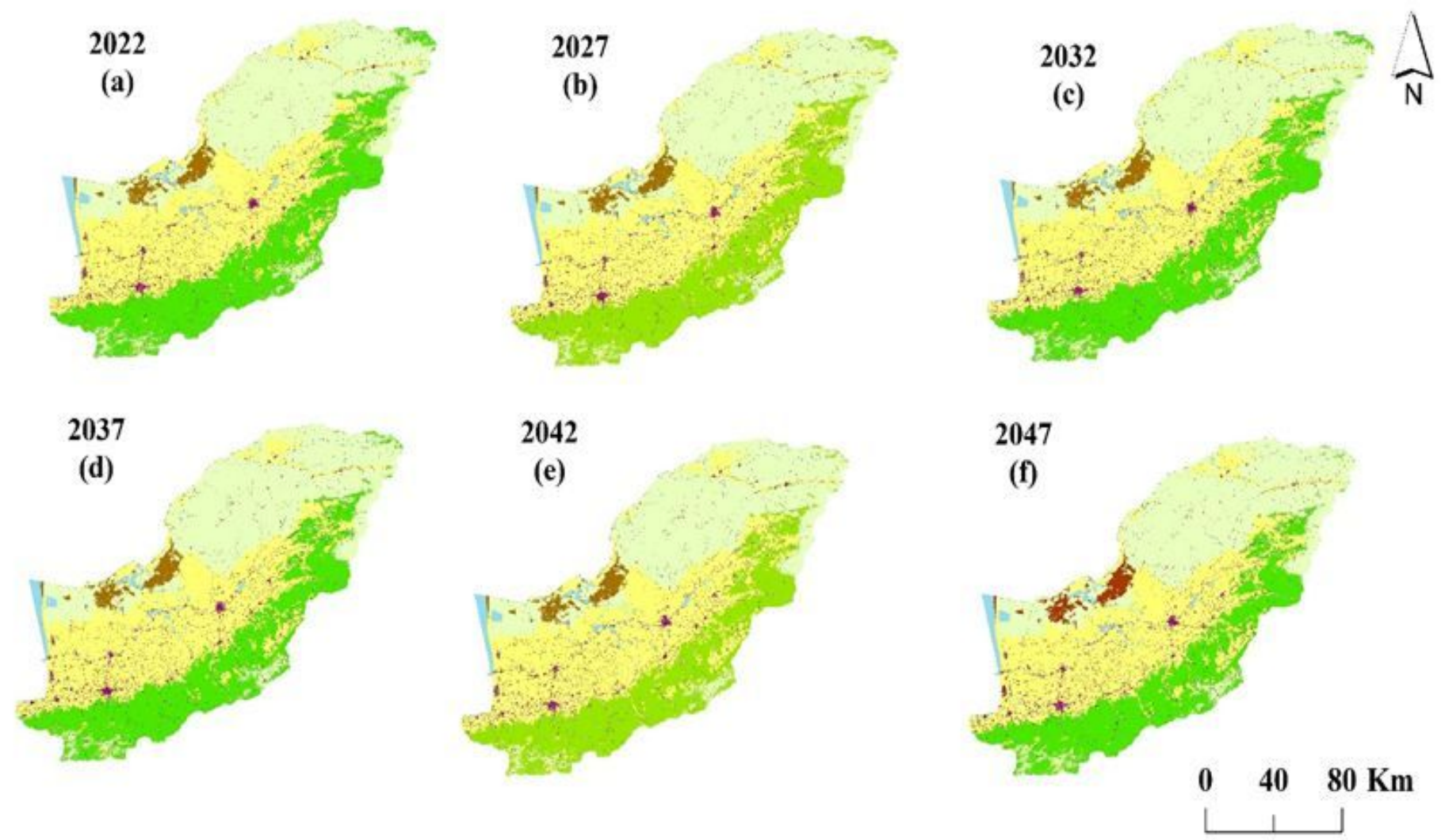

\section{Legend}

Human made Forest $\square$ Rangeland Agriculture Water Bareland

Figure 7

Predicted LULC maps of study area for (a) 2022, (b) 2027, (c) 2032, (d) 2037, (e) 2042 and (f) 2047. 


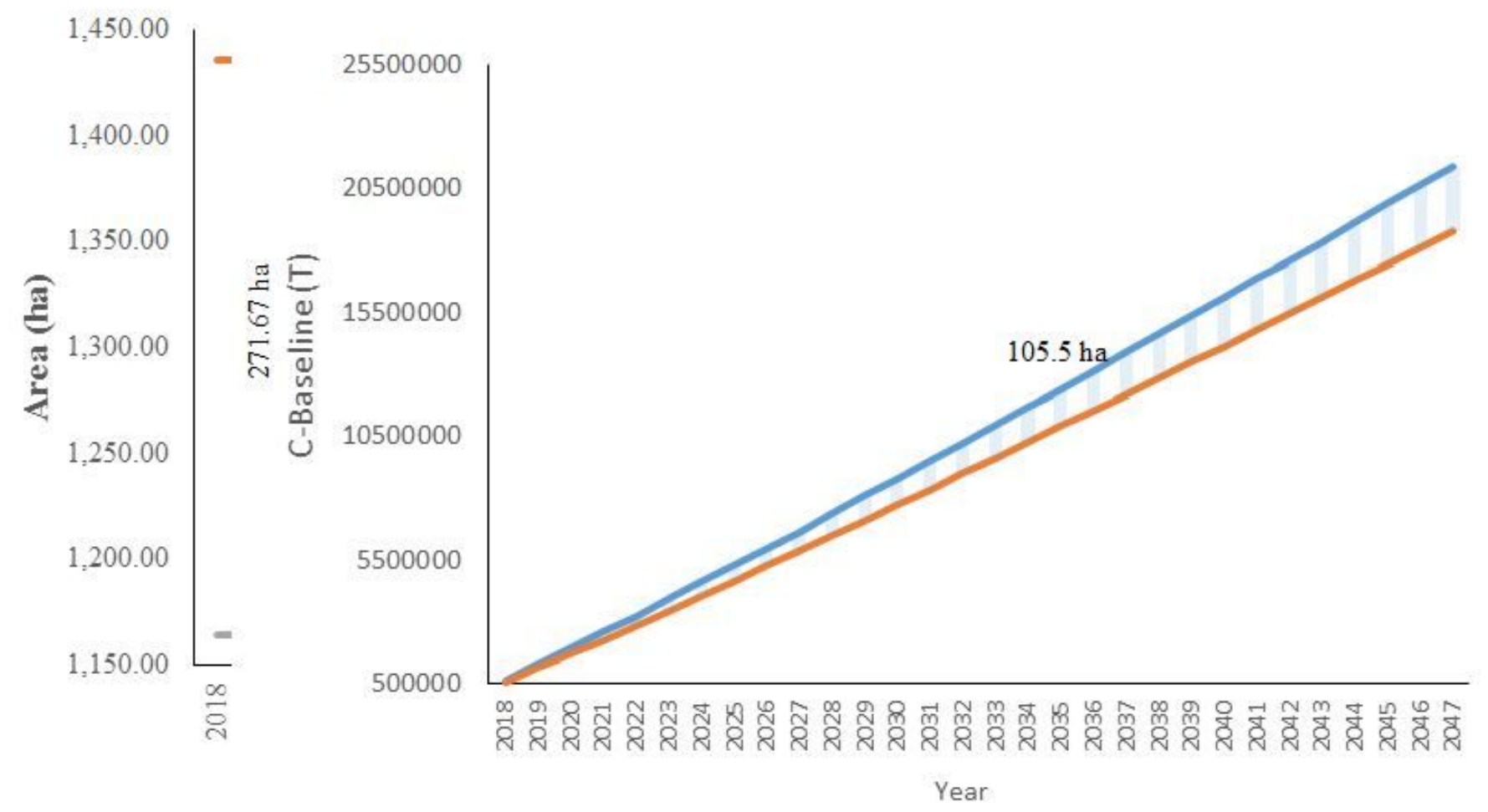

Figure 8

Destruction rate of forest cover in the project area and leakage belt.

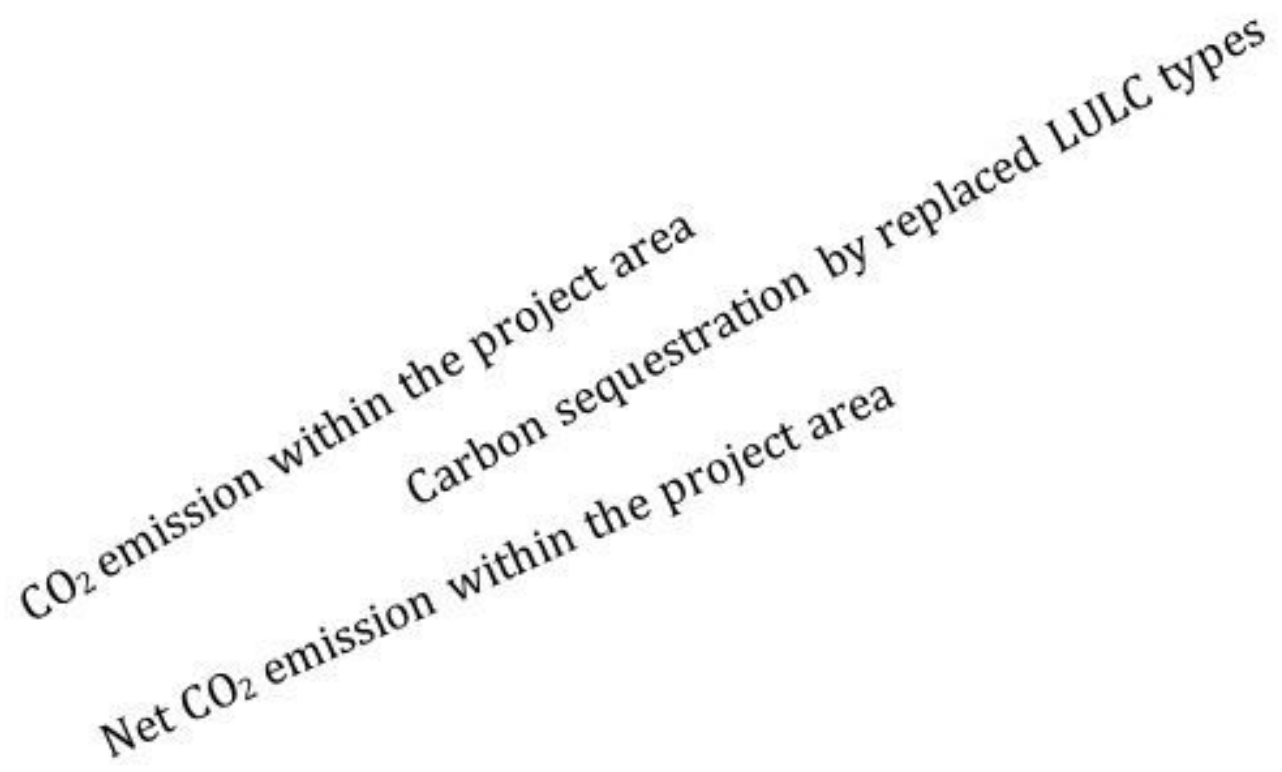

Figure 9

$\mathrm{CO} 2$ and Net $\mathrm{CO} 2$ emissions within the project area under baseline. 


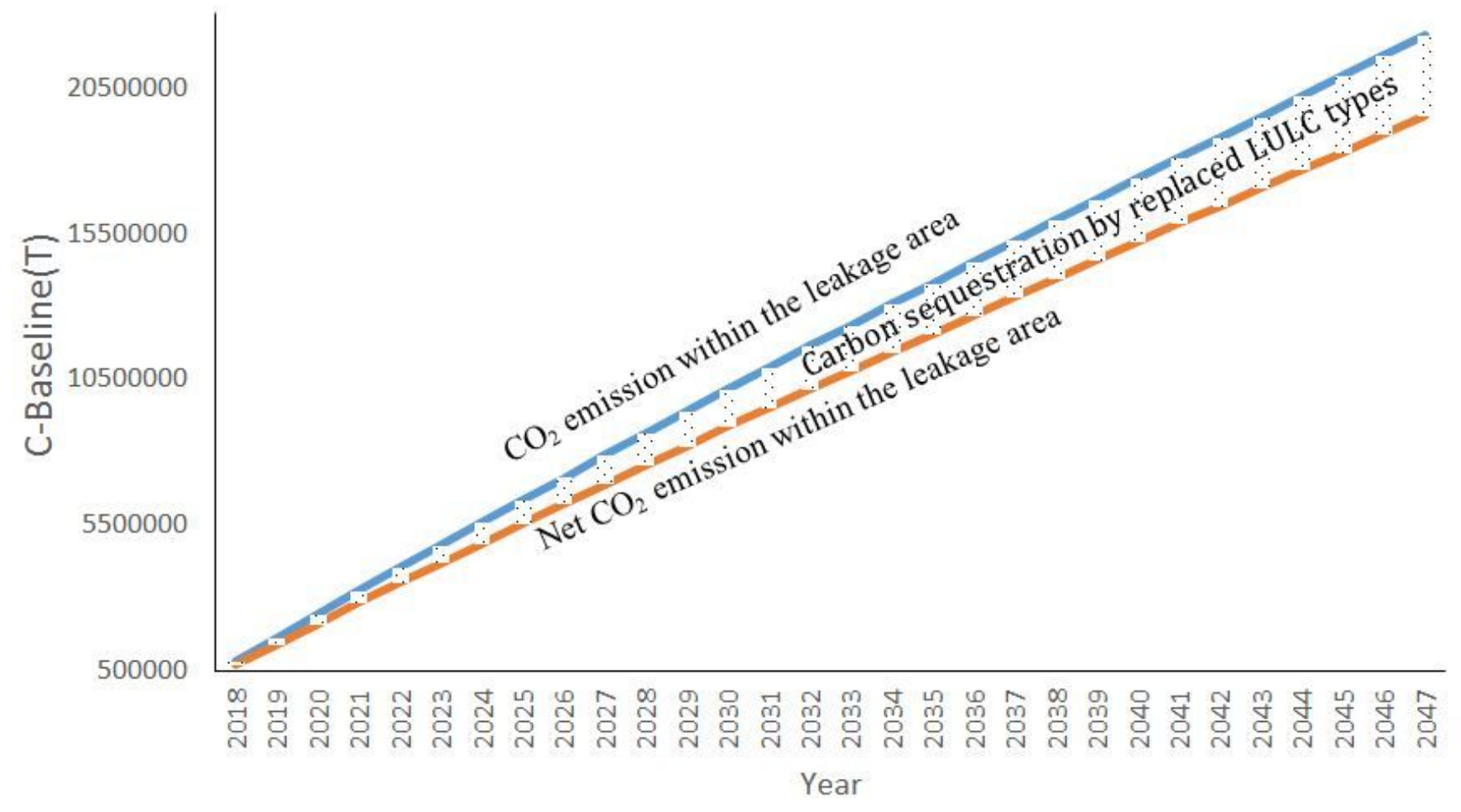

Figure 10

$\mathrm{CO} 2$ and Net CO2 emissions within the leakage area under baseline. 


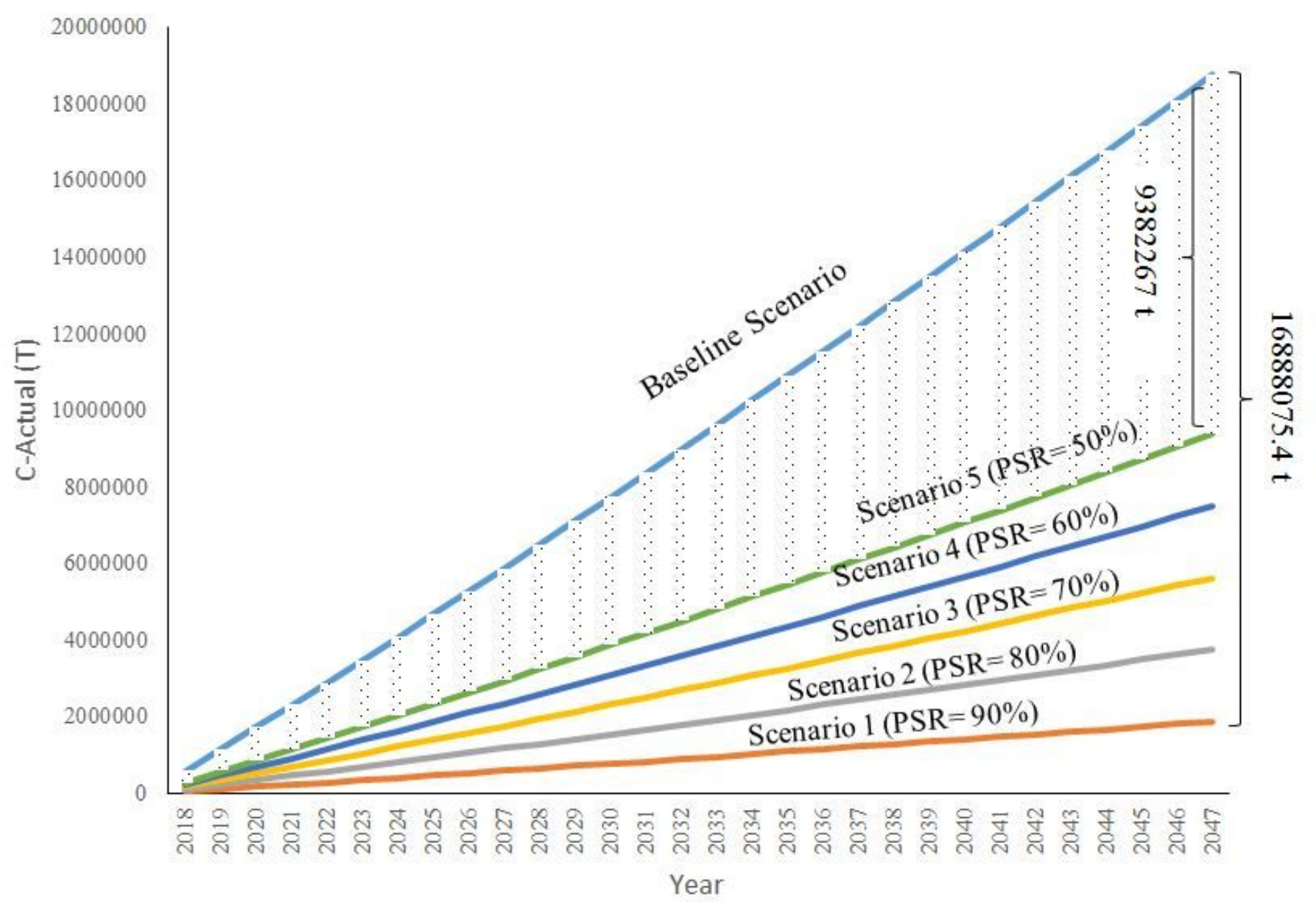

Figure 11

Estimation of C-Actual changes under the different project scenarios 


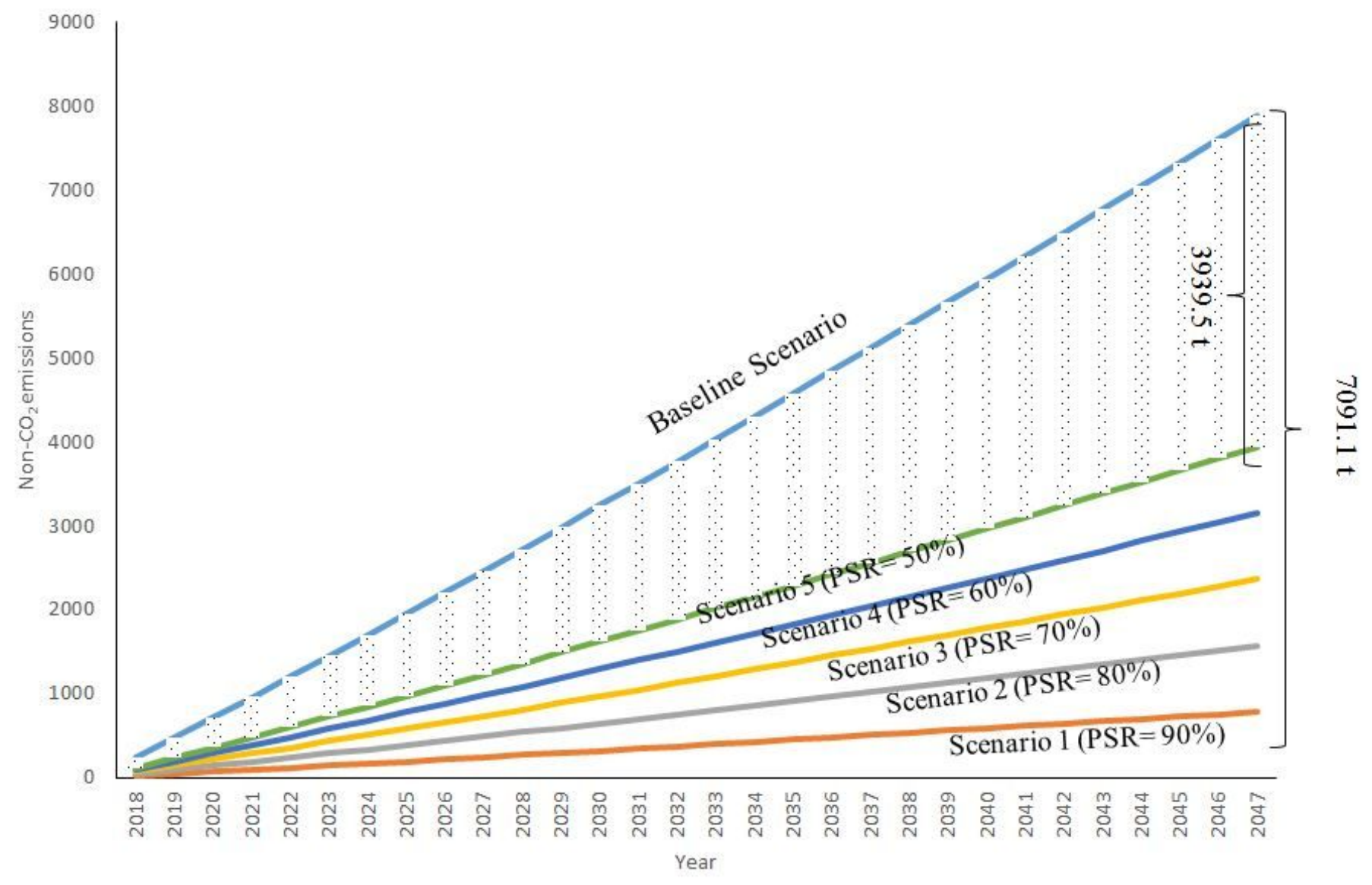

Figure 12

Estimation of non-CO2 emissions under the different project scenarios.

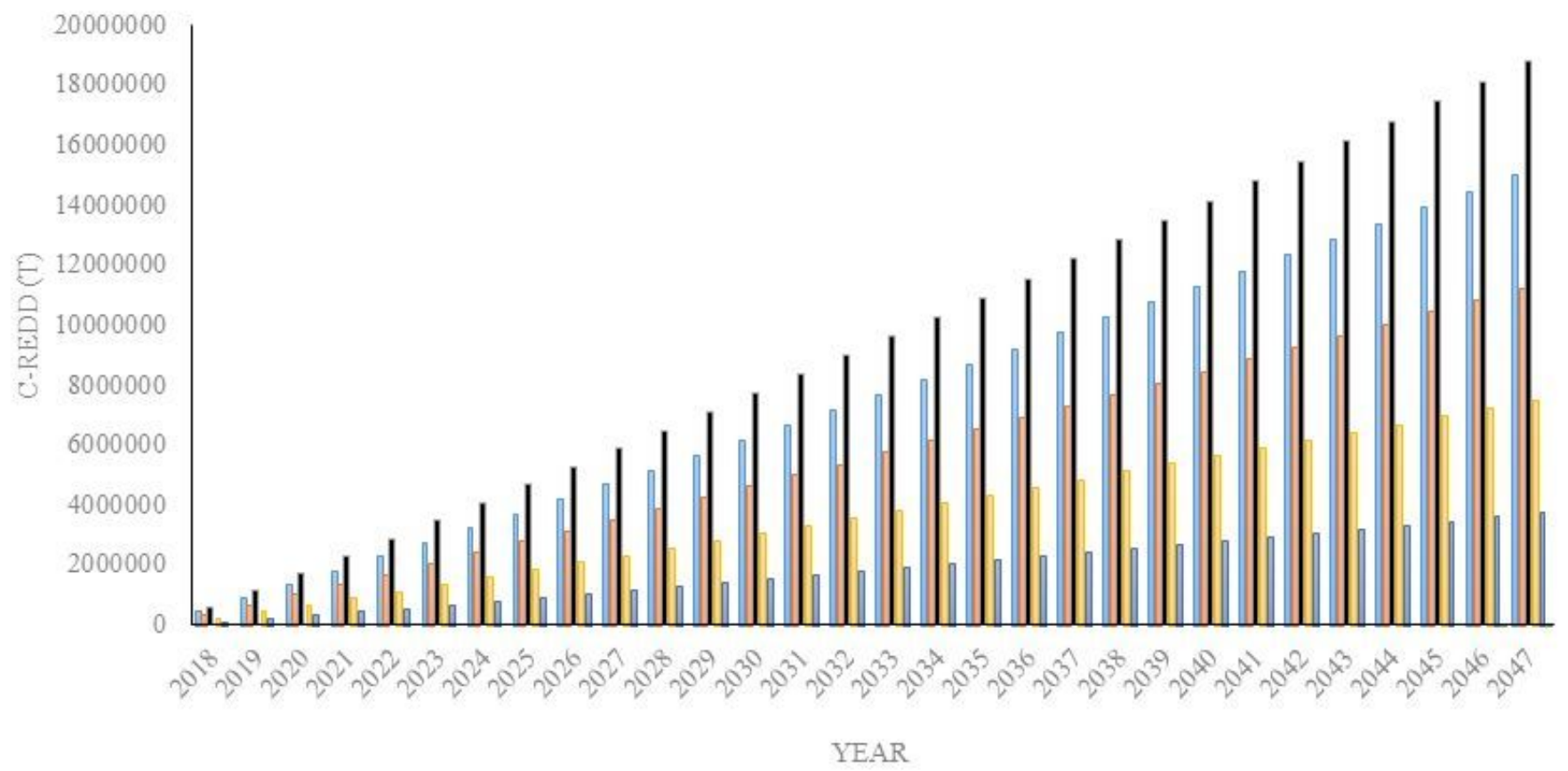

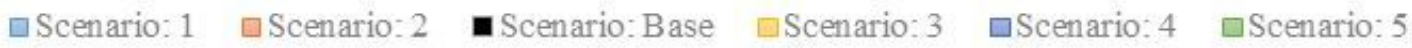


Figure 13

Net CO2 emission reduction under different project scenarios (C-REDD)

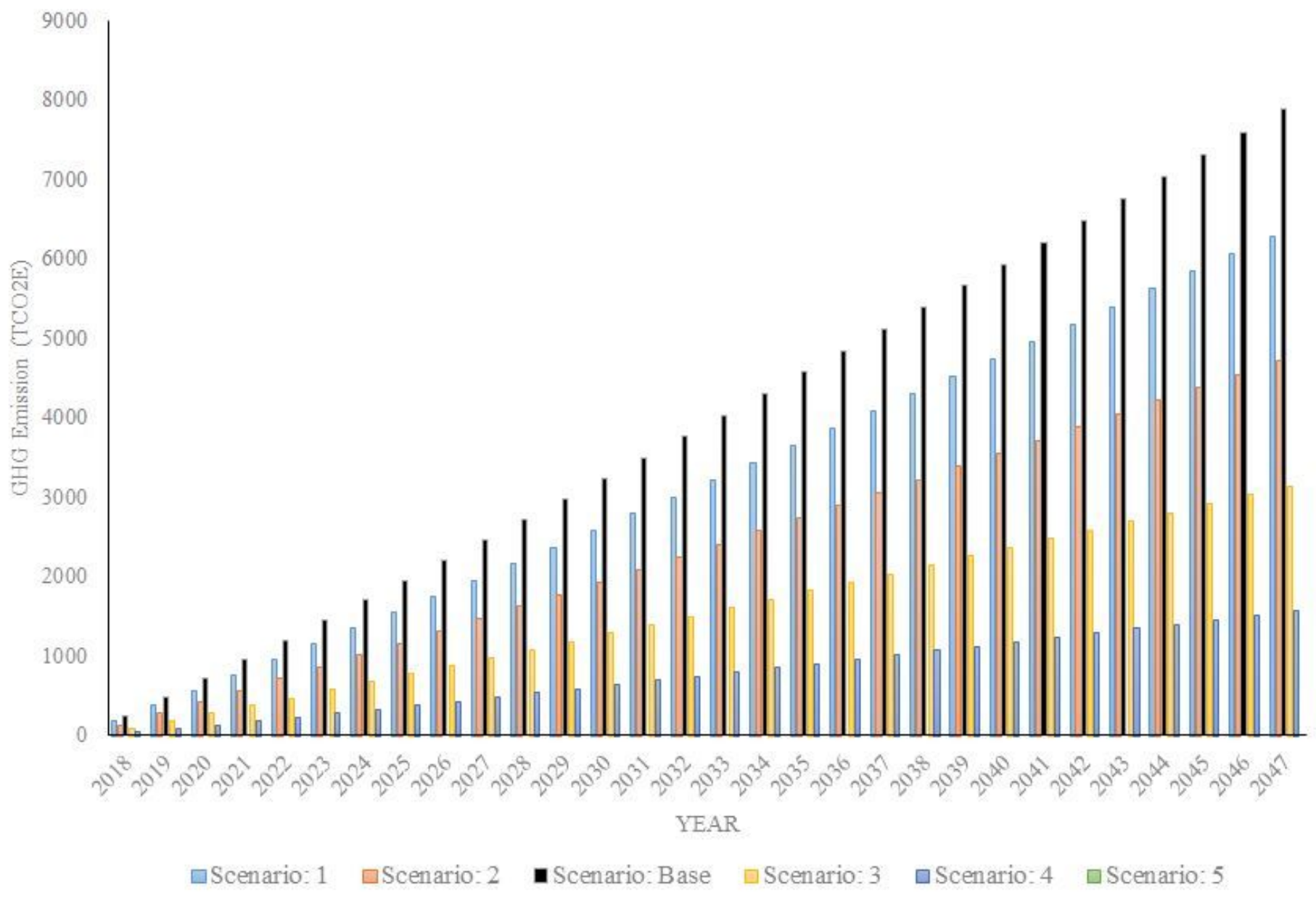

Figure 14

Net non-CO2 emissions reduction under different project scenarios. 


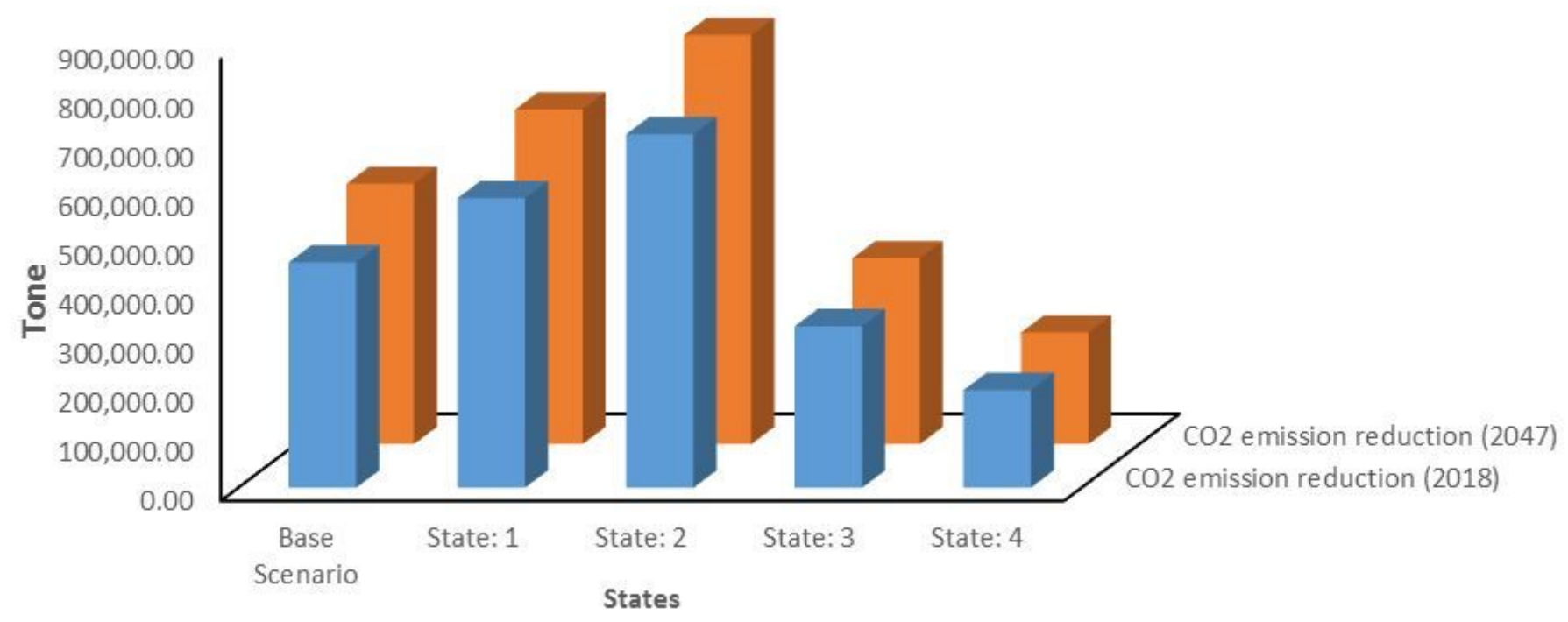

Figure 15

CO2 emissions by changing the amount of forest carbon stocks in different states.

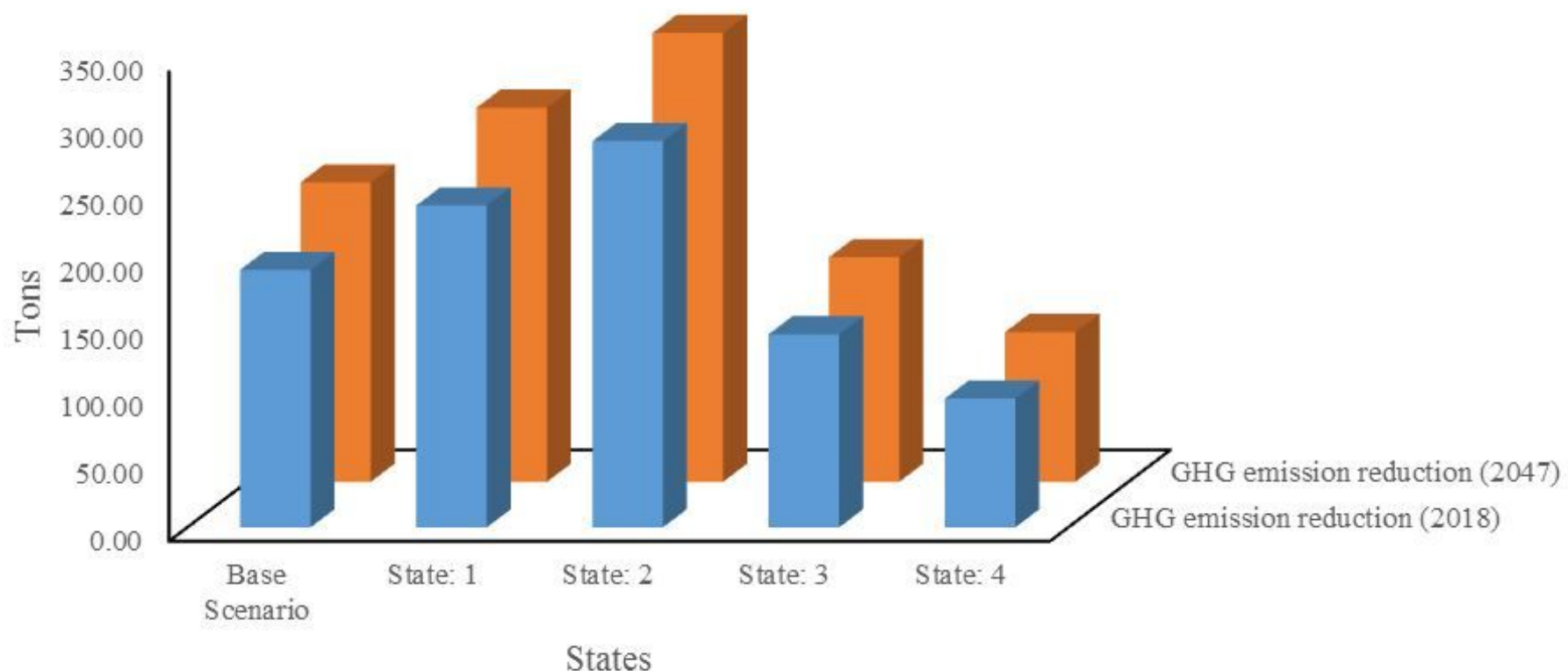

Figure 16

Non-CO2 emissions by changing the amount of forest carbon stocks in different states. 